\title{
Improving effector functions of antibodies for cancer treatment: Enhancing ADCC and CDC
}

\author{
Akito Natsume \\ Rinpei Niwa \\ Mitsuo Satoh \\ Antibody Research Laboratories, \\ Research Division, Kyowa Hakko Kirin \\ Co., Ltd.,/Machida-shi, Tokyo, Japan
}

Correspondence: Akito Natsume Antibody Research Laboratories, Research Division, Kyowa Hakko Kirin Co., Ltd., 3-6-6 Asahi-machi, Machida-shi, Tokyo, 194-8533, Japan

Tel $+8 \mid 427252555$

Fax +8I 427252689

Email akito.natsume@kyowa-kirin.co.jp

\begin{abstract}
As platforms for therapeutic agents, monoclonal antibodies (MAbs) have already been approved, and several MAbs have demonstrated clinical effectiveness in a variety of malignancies. However, several issues have also been emerging in antibody therapy, such as high cost and insufficient drug action. Recently, to improve MAb activity in humans, effector functions have been subjects of focus, especially antibody-dependent cell-mediated cytotoxicity (ADCC) and complement-dependent cytotoxicity (CDC). Extensive efforts have been made to enhance these effector functions of MAbs, and successful approaches have been reported by us and others, wherein the binding activity of MAbs to Fc $\gamma$ RIIIa or C1q is increased by introducing amino acid mutations into heavy chain constant regions or through glyco-modification of Fc-linked oligosaccharides. In addition, one of the next approaches to optimizing therapeutic antibodies would be to combine multiple enhancing modifications into a single antibody platform to overcome the diverse mechanisms of clinical resistance of tumor cells. For this aim, we have recently developed a successful combination composed of ADCC-enhancing modification by the fucose depletion from Fc-linked oligosaccharides and CDC-enhancing modification by IgG1 and IgG3 isotype shuffling in heavy chains, which could be of great value for the development of third-generation antibody therapeutics.
\end{abstract}

Keywords: ADCC, CDC, effector functions, Fc oligosaccharides, IgG isotypes, nonfucosylated $\operatorname{IgG}$

\section{Introduction: Current status of therapeutic antibodies}

Since the late 1990s, more than 20 monoclonal antibodies (MAbs) have been approved as therapeutic agents, and MAbs are emerging as a major new class of drugs that confer great benefits to patients. In fact, therapeutic antibodies have demonstrated improvements in overall survival and time to disease progression in a variety of malignancies, such as breast, colon, and hematological cancers. ${ }^{1-4}$ Recently, adding to antigen binding and specificity, "effector functions" have come under increasing focus as a cause of drug action by therapeutic MAbs in humans. In particular, Fc gamma receptor (FcyR) IIIadependent effector functions may be one of the major critical mechanisms responsible for the clinical efficacy of therapeutic MAbs; this is supported by genetic analysis of working polymorphisms of the receptor in patients. ${ }^{5-9}$ FcyRIIIa, a member of the leukocyte receptor family Fc $\gamma R$ s, is known to be a major triggering receptor of ADCC in natural killer (NK) cells. Several therapeutic MAbs are capable of ADCC, such as anti-CD20 rituximab $\left(\right.$ Rituxan $\left.^{\circledR}\right)$, anti-Her2 trastuzumab (Herceptin ${ }^{\circledR}$ ), anti-tumor necrosis factor- $\alpha$ (anti-TNF- $\alpha$ ) infliximab (Remicade ${ }^{\circledR}$ ), and anti-RhD., ${ }^{5,6-14}$ Complement-dependent cytotoxicity (CDC), another effector function of antibody, is also considered a possible anti-tumor mechanism of rituximab and alemtuzumab (Campath-1H). ${ }^{15,16}$ Furthermore, most therapeutic antibodies that have been licensed and developed as medical agents are of the human IgG1 isotype, which can induce strong ADCC and CDC when compared with the other heavy chain isotypes of the human antibody. These effector functions are 
activated through the interactions of the Fc with either FcyRs or complements, and the interactions are affected by N-linked biantennary complex-type oligosaccharides attached to the antibody Fc region, which is heavily fucosylated in human IgG1. In addition to their multifunctional activities, therapeutic MAbs of human IgG1 isotype have long-term stability in blood via a unique neonatal Fc receptor (FcRn) mechanism, which has never been seen in small molecular drugs. ${ }^{17,18}$ Thus, the MAb platform is very suitable for developing medicines based on molecular targeting. However, we have also realized a shortcoming of the current generation of therapeutic antibodies, as exemplified by the insufficient results of numerous clinical trials, especially in antibodies recognizing surface tumor antigens, and by an economically intolerable cost with multiple high-dose administration treatment even in the case of effective therapeutic antibodies. ${ }^{19-22}$ It is time to design next-generation therapeutic antibodies that can overcome these issues.

\section{Basic structure and physiological mechanism of therapeutic antibodies}

Although five classes of immunoglobulin (IgM, IgD, $\operatorname{IgG}, \operatorname{IgA}$, and $\mathrm{IgE}$ ) and four IgG subclasses (IgG1, IgG2, $\mathrm{IgG} 3$, and $\mathrm{IgG} 4$ ) are present in humans, IgG1 is primarily employed as a therapeutic agent due to its long half-life in blood (approximately 21 days) and due to its advantage in effector functions compared to those of the other Ig classes and subclasses. ${ }^{23}$ The MAbs of the human IgG1 isotype has a basic structure of $150 \mathrm{kDa}$ consisting of two immunoglobulin light chains and two immunoglobulin heavy chains in covalent and noncovalent association, resulting in the formation of three independent protein moieties - two Fab regions and one Fc region - which are connected through a flexible linker designated as the hinge region (Figure 1). Fab regions in an antibody molecule are of identical structure, wherein each expresses a specific antigen-binding site, and the Fc region expresses interaction sites for ligands which can induce effector functions, including three structurally homologous cellular Fc receptor types (Fc $\gamma R I, F c \gamma R I I, F c \gamma R I I I)$, the C1q component of the complement, and the FcRn. ${ }^{24,25}$ The physiological activities of therapeutic antibodies are mediated by two independent natural immunoglobulin mechanisms: the efficacy of therapeutic antibodies results from its specific and bivalent binding to the target antigen (eg, blockade or neutralization of target antigen or induction of apoptosis) and from effector functions that are activated only by the formation of immune complexes of the Fc and the effector ligands named above.
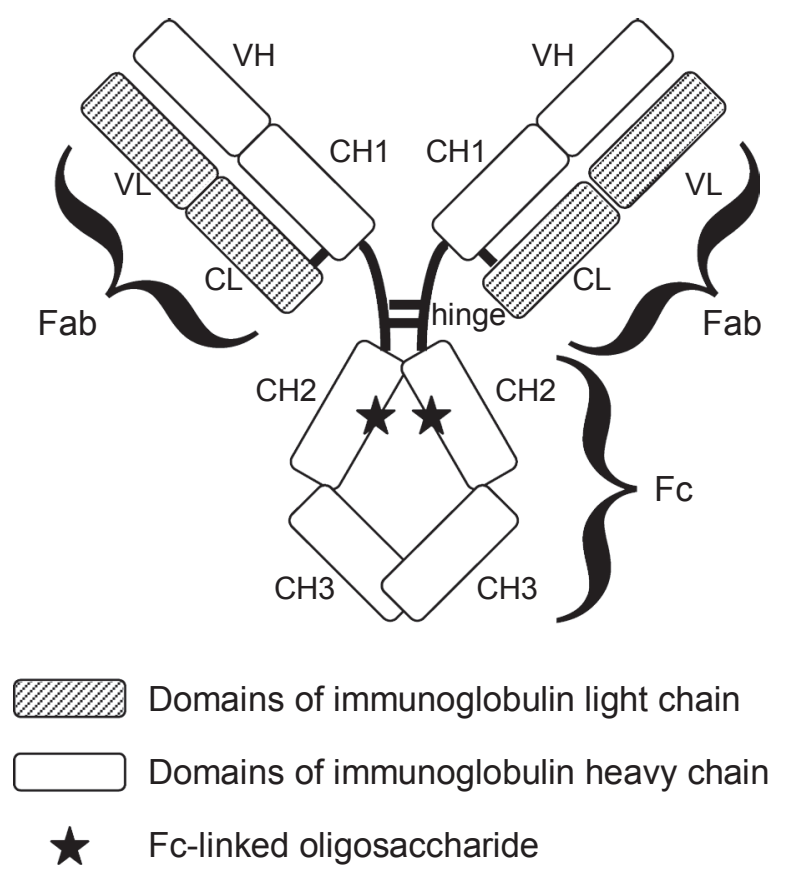

Figure I Structure of human $\lg G \mid$ antibody. The Mabs of human $|g G|$ isotype consists of two immunoglobulin light chains and two immunoglobulin heavy chains. Heavy chains are covalently paired by disulfide bonds in hinge regions, and each heavy chain is connected to a light chain by a disulfide bond between $\mathrm{CHI}$ and $\mathrm{CL}$. A pair of $\mathrm{VH}$ and $\mathrm{VL}$ in Fab regions makes an antigen binding site. In the $\mathrm{CH} 2$ domains of $\mathrm{Fc}$ regions, an oligosaccharide is covalently attached to the both domains at asparagine 297 (Asn-297).

Heavy chains are covalently paired by disulfide bonds in hinge regions, and the $\mathrm{Fc}$ region contains the $\mathrm{CH} 2$ domains and noncovalently paired $\mathrm{CH} 3$ domains (Figure 1). In the $\mathrm{CH} 2$ domains, an oligosaccharide is covalently attached to the both domains at asparagine 297 (Asn-297). The major interaction sites of the $\mathrm{Fc}$ to the effector ligands are in the hinge and $\mathrm{CH} 2$ regions, and the binding is known to depend on the glycoform of the oligosaccharides attached to the $\mathrm{CH} 2$ domains. $^{23,26}$ The effector mechanisms mediated via Fc $\gamma R I$, Fc $\gamma R I I, F c \gamma R I I I$, and C1q are severely compromised or abrogated in aglycosylated or deglycosylated forms of $\operatorname{IgG1} .^{25,27-29}$ In human IgG1, the Fc-linked oligosaccharide is of the biantennary complex type (Figure 2) and is composed of a mannosyl-chitobiose core structure in the presence or absence of a core fucose, a bisecting $\mathrm{N}$-acetylglucosamine (GlcNAc), and terminal galactose and sialic acid. This structure gives rise to heterogeneity with a mixture of 30 or more glycoforms. ${ }^{30-33}$ In general, the oligosaccharides of glycoprotein are attached to the molecular surface and thought to cover the protein portion just like a cachet. However, crystal structure analysis has revealed that the Fc-linked oligosaccharides of human IgG1 antibody are integral to the Fc region and influence the conformation of 


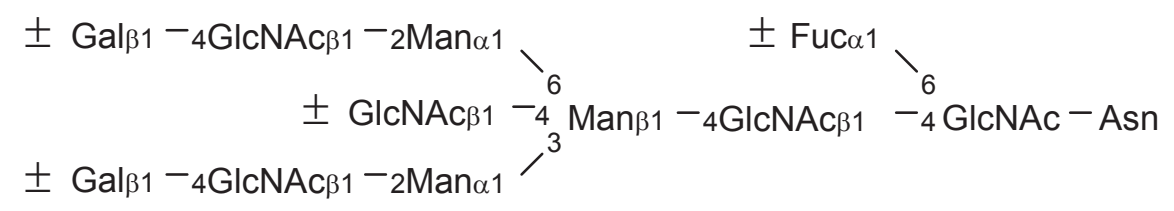

Figure 2 Fc-Linked oligosaccharides of antibodies. A conserved oligosaccharide core, linked to the Asn-297, is composed of a mannosyl-chitobiose core structure in the presence or absence of a core fucose (Fuc), a bisecting $\mathrm{N}$-acetylglucosamine (GlcNAc) and terminal galactose (Gal) and sialic acid; this structure gives rise to heterogeneity with a mixture of 30 or more glycoforms.

Abbreviations: Man, mannose monosaccharide residue.

the Fc via the multiple noncovalent interactions with the $\mathrm{CH} 2$ domains. ${ }^{34-36}$ Therefore, the oligosaccharide influences the Fc structure, and there are suitable oligosaccharide structures among the natural heterogeneity of the Fc-linked oligosaccharides for the binding between Fc and effector ligands. For example, human IgG1 antibodies bearing the Fc-linked oligosaccharides lacking core fucose show improved binding to Fc $\gamma$ RIIIa and much enhanced ADCC compared to fucosylated ones. ${ }^{37}$

\section{Importance of ADCC on the clinical efficacy of therapeutic antibodies}

There is a substantial discrepancy between the potency of therapeutic antibodies in vitro and in vivo in terms of the required doses, especially in the anticancer therapies. Cancer patients treated with therapeutic antibodies typically need to receive weekly doses of several hundred milligrams over several months to maintain an effective serum concentration of over $10 \mu \mathrm{g} / \mathrm{ml} .{ }^{38-40}$ On the other hand, the maximal in vitro cellular cytotoxicity by ADCC of these therapeutic antibodies can be achieved at an antibody concentration of less than $10 \mathrm{ng} / \mathrm{mL}$, which is several orders of magnitude below the targeted serum concentrations in vivo. ${ }^{41,42}$ This discrepancy - that is, the low in vivo efficacy of therapeutic antibodies in contrast to the high in vitro cytotoxicity is primarily due to competition between human serum $\mathrm{IgG}$ and therapeutic antibodies for binding to FcyR on effector cells; namely, endogenous human serum IgG strongly inhibits ADCC induced by therapeutic antibodies. ${ }^{43-46}$ Although the importance of antibody effector functions of ADCC on the clinical efficacy of therapeutic antibodies has long been a matter of debate, recent clinical evidence based on genetic analysis of FcyR polymorphisms in cancer patients treated with anti-CD20 rituximab and anti-HER2 trastuzumab therapies has suggested the importance of ADCC. ${ }^{5,6,9-11}$ The superior clinical response of patients carrying the high-affinity Fc $\gamma$ RIIIa allotype (FcyRIIIa-158Val) for anti-CD20 rituximab has been demonstrated, in contrast to that of patients carrying the low-affinity allotype (Fc $\gamma$ RIIIa-158Phe)..$^{5,6,9,10}$ Breast cancer patients who responded to anti-HER2 trastuzumab with complete or partial remission have been found to have a higher capability to mediate in vitro ADCC by trastuzumab than nonresponders. ${ }^{11}$ A significant correlation has also been reported between the clinical responses of the therapies and the polymorphisms of low-affinity Fc $\gamma \mathrm{R}$ in some diseases, such as rituximab-treated patients with systemic lupus erythematosus (SLE) and Waldenstrom's macroglobulinemia, Crohn's disease patients treated with anti-TNF- $\alpha$ infliximab, and pregnant women with fetal hemolytic disease treated with anti-RhD. ${ }^{9,12-14}$ Thus, the importance of ADCC for the clinical efficacy of therapeutic antibodies is now widely recognized, and ADCC enhancement technology is expected to play a key role in the development of next-generation therapeutic antibodies with improved clinical efficacy.

\section{ADCC-enhancing technology} Artificial amino acid modifications in the Fc The effector functions of an antibody can be manipulated by engineering amino acid sequences of the constant regions. In particular, facilitating Fc $\gamma$ RIIIa binding by mutated antibody sequences may be of therapeutic value. Thus, amino acid alterations in the Fc that possess improved Fc $\gamma$ RIIIa binding and resultant ADCC-enhancing capacity have been extensively studied, mainly by biotech companies, using random or rational designing approaches with high-throughput protein expression systems. A group at Genentech has discovered variant Fcs with enhanced ADCC-inducing capacity having up to three mutations, based on a comprehensive alanine scanning method on the accessible surface of the Fc. ${ }^{47}$ The Xencor group has employed a computational design algorithm and found a set of Fc variants with extremely strong FcgRIIIa binding (up to $>100$-fold enhancement in KD), which showed a strong cytotoxic activity in cynomolgus monkeys. ${ }^{48}$ The Macrogenics group has also described Fc mutants with enhanced ADCC by using a unique yeast display system. ${ }^{49,50}$ 


\section{Removal of fucose from Fc-linked oligosaccharides}

It is widely recognized that the core fucose of Fc-linked oligosaccharides greatly affects the ADCC of therapeutic antibodies and the removal of the fucose markedly enhances the ADCC via improved FcyRIIIa binding without altering antigen binding or CDC. ADCC enhancement by fucose removal is now considered a very important technique for the development of therapeutic antibodies mediating ADCC. ${ }^{21,37,41,42,45,51-63}$ The MAbs of IgG1 bearing the biantennary-complex type of Fc-linked oligosaccharides lacking core fucosylation exerts the strongest ADCC in a comparison of glycoforms. ${ }^{51}$ In human IgG, Fc-linked oligosaccharides lacking core fucose exist as portions of naturally occurring heterogeneities, and therefore there is little concern regarding its intrinsic immunogenicity. ${ }^{31,32}$ Importantly, the enhancement of ADCC by the core fucose removal is thought to leach the saturated level, according to a study wherein no significant difference in ADCC was detected between the ADCC-enhanced IgG1 by either the core fucose removal or amino acid mutations S239D/ S298A/I332E, which have higher FcyRIIIa binding affinity. ${ }^{60}$ Moreover, no additive effect is shown on the B-cell depletion activity of anti-CD20 IgG1 rituximab in human blood by the combination of these techniques, although an additive increase in Fc $\gamma$ RIIIa binding is observed in a BIAcore biosensor analysis. Thus, the enhanced Fc $\gamma R I I I a$ binding of nonfucosylated antibodies appears to be sufficient to maximize the ADCC of therapeutic antibodies without introducing artificial amino acid mutations. Furthermore, the nonfucosylated antibodies have achieved high effector activity at low doses, against tumor cells expressing low levels of antigen, or even in NK cells harboring the low-

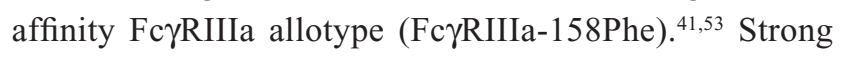
ADCC enhancement of the nonfucosylated therapeutic antibodies has also been demonstrated in the analysis using NK cells derived from breast cancer patients. ${ }^{54}$ These results showing ADCC enhancement are well reflected by in vivo analysis. The superior in vivo efficacy of nonfucosylated antibodies has also been demonstrated in the mouse model of engrafted human peripheral blood mononuclear cells (PBMC), and nonfucosylated antibodies have shown improved B-cell depletion activity in human blood analysis in vitro despite the strong inhibitory effects of human serum IgG molecules. ${ }^{21,42,45,51}$ In spite of the great benefits of nonfucosylated antibodies, currently licensed therapeutic antibodies are composed of a mixture of fucosylated and nonfucosylated immunoglobulin molecules (over $90 \%$ of the
Fc-linked oligosaccharides are fucosylated) and therefore unfortunately fail to achieve optimized ADCC due to the competition between the two forms for the antigens on the target cells..$^{21,45,51}$ This is the case because the construction of a robust process for the production of therapeutic antibodies lacking core fucosylation has proven to be a challenge..$^{64,65}$ However, the manufacture of recombinant therapeutic antibodies fully lacking core fucosylation with a fixed quality has been achieved through gene engineering of the fucosylation pathway in the cells for antibody production. ${ }^{52,66-68}$ The application of nonfucosylated antibodies is expected to be among the most powerful and elegant approaches to improving the efficacy of therapeutic antibodies, and the use of cells with $\alpha$-1,6-fucosyltransferase gene (FUT8) knockout is one of the most successful approaches for the manufacture of nonfucosylated antibodies (Potelligent technology). Nonfucosylated products manufactured using this approach have already been entered into multiple clinical trials.

\section{CDC as an effector function of therapeutic MAbs}

CDC is a cytolytic cascade mediated by a series of complement proteins abundantly present in serum. It is triggered by the binding of $\mathrm{C} 1 \mathrm{q}$ to the constant region of cell-bound antibody molecules (Figure 3). For the induction of strong CDC activity, various biological and structural features of antigen molecules are required, such as relatively high expression, the presence of small or folded extracellular portions, or epitopes that retarget antigens into lipid rafts in the case of anti-CD20 MAbs. ${ }^{69,70}$ In addition, CDC is negatively regulated by complement-regulatory proteins (CRPs: CD46, CD55, and CD59) expressing on the cell surface. ${ }^{71,72}$ The relationship between complement activation and therapeutic activity is also suggested in several reports. For example, Kennedy and colleagues have reported rapid complement consumption after rituximab administration, and Treon and colleagues have reported upregulation of CRPs in returning tumor cells after rituximab treatment. ${ }^{73,74}$

\section{CDC-enhancing technologies}

The binding of the C1q component to the Fc, the initial step of the complement cascade, affects the intensity of the following complement activation, and several approaches have succeeded in enhancing $\mathrm{CDC}$ by facilitating the binding of the antibody constant region to $\mathrm{C} 1 \mathrm{q}$. As a result of engineered amino acid mutations inserted into either $\mathrm{Fc}$ or the 


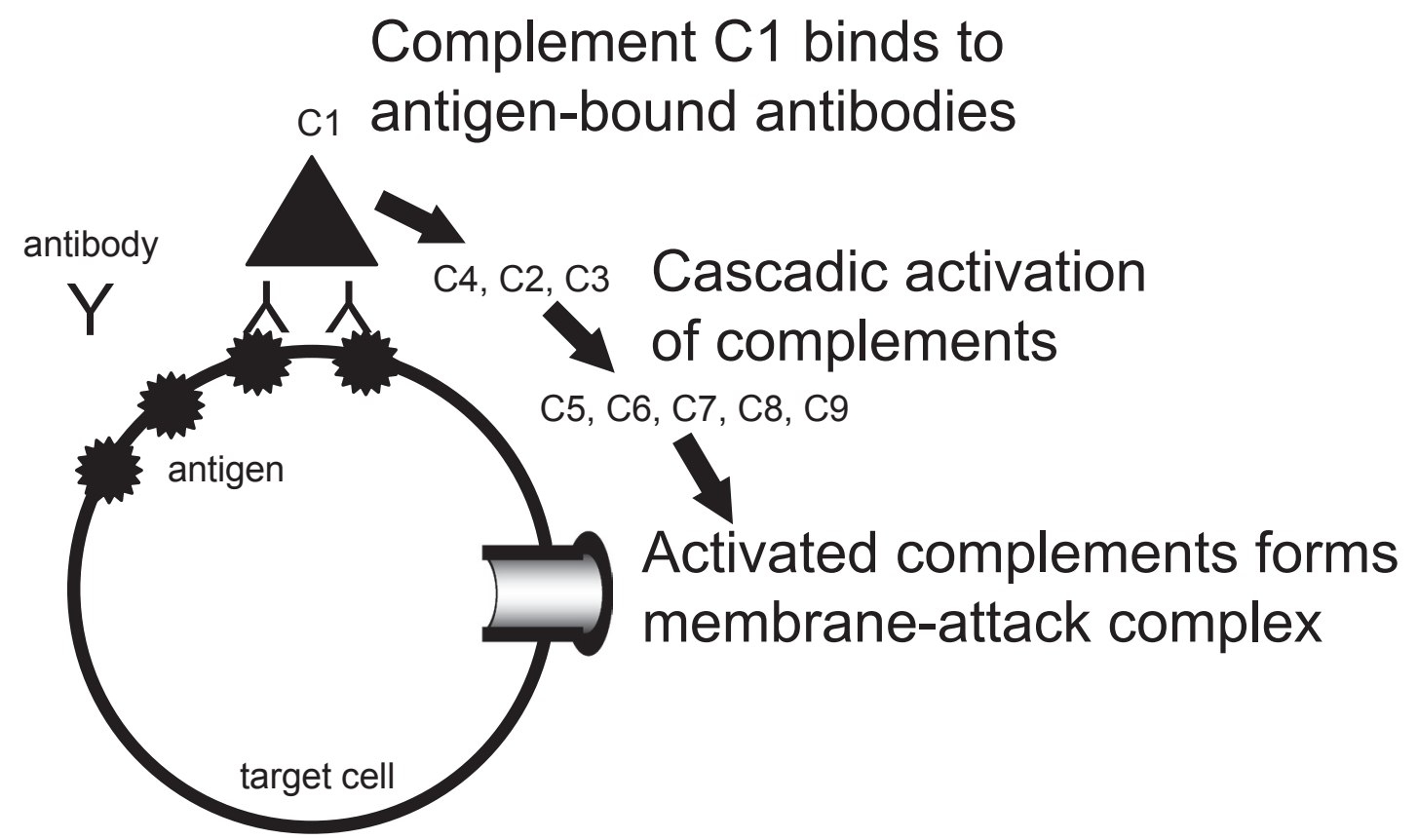

Figure 3 Schematic diagram of $C D C . C D C$ is a cytolytic cascade mediated by a series of complement proteins abundantly present in serum. It is triggered by the binding of $\mathrm{Cl}$, a subunit of $\mathrm{Cl}$, to the constant region of cell-bound antibody molecules. Finally, activated complements form menbrane-attack complex, perforating membrane.

hinge region, designed antibody constant regions possessing improved C1q binding have been achieved..$^{75,76}$

Another example of CDC enhancement is the engineering of the heavy chain by shuffling IgG1 and IgG3 sequences within a heavy chain constant region, as recently reported by our group; this is called Complegent technology (Figure 4). ${ }^{77}$ Apart from amino acid and structural idiosyncrasies, the four isotypes of human $\mathrm{IgG}$ differ from each other in the potencies of effector functions and other activities. ${ }^{41,78-82}$ In general, the rank orders of potency are $\mathrm{IgG} 1 \geqq \operatorname{IgG} 3 \gg \mathrm{IgG} 4 \geqq \operatorname{IgG} 2$ for $\mathrm{ADCC}$ and $\mathrm{IgG} 3 \geqq \mathrm{IgG} 1 \gg \mathrm{IgG} 2 \fallingdotseq \mathrm{IgG} 4$ for CDC. ${ }^{6,56,78-81}$ As a result of the comparison of a comprehensive set of structural shuffling between IgG1 and IgG3, the mixed isotype heavy chain variant, wherein a part of the Fc portion of human IgG1 heavy chain is converted into the corresponding part of human IgG3 (Complegent), showed unexpectedly strong C1q binding and CDC that was even better than those of parental IgG1 and IgG3. ADCC of the Complegent antibody was unchanged from that of parent IgG1 antibody. Furthermore, an anti-CD20 antibody with Complegent-type constant regions have shown improved B-cell depletion in cynomolgus monkeys compared to anti-CD20 IgG1. ${ }^{77}$ As a result of single intravenous injection, significant enhancement in the levels of B-cell depletion was observed for Complegenttype antibody, which was manifested in a significant delay in time to recovery of B cells. This approach succeeded in enhancing CDC also in the therapeutic anti-CD52 antibody alemuzumab, and thus may be applicable to a wide range of target molecules.

\section{Enhancement of multiple anti-tumor functions: The next target of antibody optimization?}

As discussed above, antibody effector functions can be manipulated by engineering amino acid sequences of the constant regions. Amino acid alterations in the Fc that possess improved Fc $\gamma$ RIIIa binding and resultant ADCC-enhancing capacity have been extensively studied and successfully obtained by mutational or computational analyses on the Fc: FcyRIIIa contact site or by direct evolutional methods using a comprehensive display library. ${ }^{47,48,50,83}$ Similarly, binding to $\mathrm{C} 1 \mathrm{q}$ or the neonatal Fc receptor, which is involved in IgG clearance, can also be improved by introducing amino acid mutations into the Fc or the hinge. ${ }^{75,76,84,85}$ Typically, these variant Fcs require at least 2 to 5 amino acid alterations from unmutated wild-type sequences.

One of the next directions for the optimization of therapeutic antibodies would be to combine multiple enhancing modifications into a single antibody platform. In theory, different Fc modifications can be "piled up" to create a variant sequence having accumulated amino acid mutations that possess multiple enhanced functions. Stavenhagen and colleagues have reported a successful example of an engineered $\mathrm{Fc}$ sequence having five amino acid mutations and 


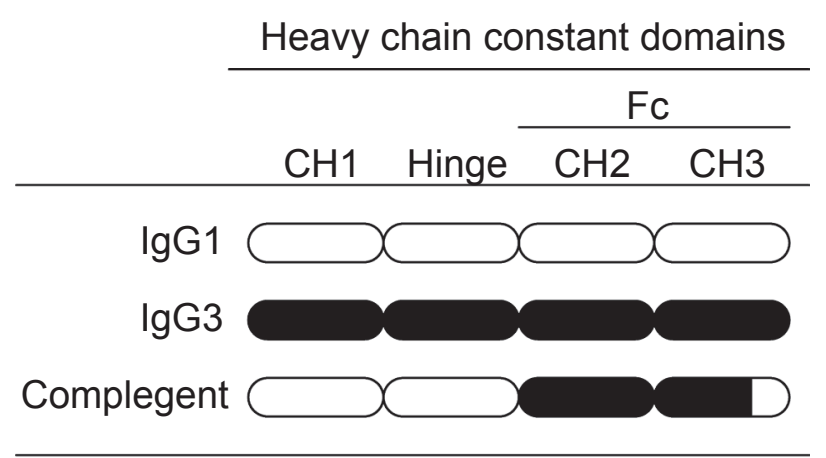

\section{$\longrightarrow$ Domains of human $\lg \mathrm{G} 1$ Domains of human $\lg G 3$}

Figure 4 Scheme of the mixed isotype heavy chain. In the mixed isotype heavy chain variant, a part of the Fc portion of human lgGI heavy chain is converted into the corresponding part of human lgG3 (Complegent).

possessing enhanced binding capacity to both Fc $\gamma$ RIIa and FcyRIIIa. ${ }^{50}$ Nevertheless, the effect of combining multiple sets of amino acid alterations would be difficult to predict, probably because the conformational change of overall antibody molecules could lead to unexpected changes in some biological activities. Actually, artificial Fe mutations have often been reported to induce unpredictable functional impairments; for example, a reduction in Fc $\gamma$ RIIIa-binding activity is often seen for the Fc mutations that improve antibody binding to C1q, Fc $\gamma$ RII, or FcRn. ${ }^{47,75,85}$ Notably, these unpredictable phenomena did occur even though the Fc $\gamma$ RIIIa contact sites of IgG did not always overlap with other contact sites, especially for those of FcRn (located in the $\mathrm{CH} 2: \mathrm{CH} 3$ cleft), which seem to be far apart from the Fc $\gamma$ RIIIa binding sites (located between the two lower hinges. ${ }^{35,86,87}$

Despite such technical limitations, many companies have made extensive progress in developing the next-generation anti-CD20 antibodies since the successful launch of rituximab. Now multiple new anti-CD20 antibodies with diverse effector functions are beginning to enter clinical trials (Table 1).
Many of the new anti-CD20 antibodies are designed to improve the ADCC of rituximab. Some of them might be attributable to the inherent properties of parent antibodies different from those of rituximab (clone 2B8). Interestingly, some antibodies possess engineered constant regions with increased ADCC-inducing capacity, either by mutating amino acid sequences of the Fc (AME-133) or by engineering the glycoform of the Fc-linked oligosaccharides (GA101).

\section{AccretaMAb platform:A universal platform technology for the next generation of therapeutic antibodies with enhanced ADCC and CDC}

An important feature of Potelligent technology is that it can be applied to a broad spectrum of antibody backbone structures. This ADCC-enhancing effect of defucosylation was initially found for human IgG1 background, and was then expanded to include various types of immunoglobulins (other human IgG subclasses or murine IgG2) and antibody-like engineered molecules (Fc fusion proteins). ${ }^{37,55-57,59,92}$ In every case examined, fucose removal did not seem to influence any biological activities other than FcyRIIIa-related functions. Although fucose removal from antibody oligosaccharides is associated with a significant thermodynamic change in the Fc $\gamma$ RIIIabinding state of IgG1, ${ }^{62}$ it does not significantly influence the overall IgG1 conformation except for a small change in the hydration mode around the fucose residue as revealed by crystal structure and NMR analyses. ${ }^{63}$ It is likely that the minimal conformational change allows this phenomenon to be easily applied to a wide range of antibody species.

More recently, we have shown that fucose removal from Complegent antibodies (IgG1/IgG3 chimeric isotype antibodies), in what we call the AccretaMAb platform, results in the full retention of potent $\mathrm{ADCC}$ and $\mathrm{CDC}$, to levels that are comparable to those seen for Potelligent

Table I Effector functions of selected next-generation anti-CD20 MAbs

\begin{tabular}{llllll}
\hline Antibody & Developer & Type & Parent MAb & $\begin{array}{l}\text { Effector functions in comparison } \\
\text { with rituximab }\end{array}$ & Reference \\
\hline Ofatumumab & GSK/Genmab & $\operatorname{lgGl}$ & $2 \mathrm{~F} 2$ & Potent CDC & 88 \\
Ocrelizumab & Genentech & $\operatorname{lgGI}$ & $2 \mathrm{H} 7$ & Potent ADCC and decreased CDC & 89 \\
Veltuzumab & Immunomedics & $\operatorname{lgGI}$ & $2 \mathrm{~B} 8$ & Comparable to rituximab & 90 \\
AME-I33 & AME & Mutated IgGI & Synthetic & Potent ADCC & 83 \\
GAI0I & Roche/GlycArt & Glycoengineered IgGI & BI & Potent ADCC/direct apoptosis, no CDC & 9 I \\
\hline
\end{tabular}


or Complegent alone, respectively. ${ }^{77}$ The successful combination of ADCC- and CDC-enhancing modifications in the AccretaMAb platform is constituted by two essential structural factors: (i) IgG1/IgG3 mixed constant regions that enhance $\mathrm{C} 1 \mathrm{q}$ binding and $\mathrm{CDC}$ activity, and (ii) nonfucosylated oligosaccharides linked to the Fc of the mixed variant constant regions that maximize its ADCC.

As for the structural basis of AccretaMAb, how the IgG1/IgG3 chimeric isotype sequence greatly enhances CDC activity remains elusive. Interestingly, in addition to the hinge derived from IgG1 and the $\mathrm{CH} 2$ from $\mathrm{IgG} 3$, the other constant domains (the $\mathrm{CH} 1$ from $\mathrm{IgG} 1$ and the $\mathrm{CH} 3$ from $\mathrm{IgG} 3$ ) are also required for its optimized $\mathrm{CDC}$ activity. The $\mathrm{CH} 1$ and the $\mathrm{CH} 3$ domains are not considered direct contact sites between IgG:C1q, as revealed by a comprehensive structural shuffling analysis between IgG1 and IgG3 ${ }^{77}$ Thus it appears likely that the specific combinations of multiple IgG domains of different subclasses render the overall variant antibody conformation capable of binding $\mathrm{C} 1 \mathrm{q}$ with unexpectedly strong affinity. Importantly, the FcyRIIIa binding and the ADCC of this novel chimeric constant region are as strong as those of IgG1, and can be further maximized by the removal of fucose from Asn297-linked oligosaccharides. ${ }^{77}$

\section{Clinical implication of engineered antibodies with multiple-enhanced functions}

It has been suggested that tumor cells avoid attack from therapeutic antibodies by using various mechanisms, which might lead to insufficient efficacy in the clinic (Table 2).

Thus, in order to overcome the diverse mechanisms underlying clinical resistance by tumor cells, the enhancement of multiple functions of therapeutic antibodies might be a promising approach. Regarding AccretaMAb, for example, the dual enhancement of effector functions (ADCC and CDC) is expected to bring some additional advantages; these two functions might act complementarily. For instance, tumor cells that are highly resistant to attack by complementary regulatory proteins would be destroyed more effectively by potent ADCC due to defucosylated Fc-linked oligosaccharides. Conversely, in circumstances where the accessibility of ADCC effector cells is severely limited by tight solid tumor tissues, the potent CDC of AccretaMAb, which does not require cellular factors, would be a powerful weapon for eliminating tumor cells.

Furthermore, the increased complement fixating and enhanced ADCC activities might have a synergistic effect through an interaction between complement opsonized on the target cells and complement receptors (eg, CR3) present on effector cells, which would increase ADCC of antibodies. However, the clinical importance of this mechanism is far less validated and remains to be elucidated..$^{93}$

One of the potential issues in future therapy with artificially engineered antibodies is immunogenicity; namely, the use of mutated sequences may increase the risk of newly generated non-self peptides that bind to MHC class II molecules, especially for those having a higher number of accumulated amino acid alterations. Interestingly, the AccretaMAb platform is fully composed of natural structural components: IgG1 and IgG3 sequences and nonfucosylated $N$-linked oligosaccharides (constitutes $\sim 10 \%$ of human serum IgG oligosaccharides). ${ }^{94}$ Future clinical trials of AccretaMAb will also confirm the hypothesis that the variant constant regions consisting of fully natural components would render the antibodies potentially less immunogenic compared to artificial mutation approaches.

\section{Perspectives}

After a number of successes and failures in the lab, engineered antibodies with optimized effector functions now

Table 2 Proposed mechanisms of resistance by tumor cells to antibody therapy

(i) Tumor factors

Poor penetration of effector cells of ADCC into solid tumor tissues

Complement-regulatory proteins (CD46, CD55, and CD59) on the tumor cells

Soluble antigens

Altered signaling (eg, bcl-2 elevation in rituximab therapy)

(ii) Host factors

- Heterogeneity in ADCC according to FcyRIlla functional polymorphism

Inactivation of effector cells in patients (eg, downregulation of $\zeta$ chain, NKG2D, NKp30, NKp44, or NKp46 in NK cells)

(iii) Therapy factors

Suppression of effector cells by chemotherapy 
appear to be coming of age as pharmaceuticals. Now many believe that enhancing ADCC is one of the most promising ways to improve the clinical efficacy of already-approved antibodies, and this concept is actively being examined in the clinic, especially in the field of hematological malignancy treatment. However, considering the limited efficacy of therapies with already-approved antibodies especially for solid tumors (eg, cetuximab, bevacizumab, and trastuzumab), in which only small percentages of patients can achieve a partial response and most responders will relapse when given as monotherapy - there remains a critical need to improve the anti-tumor mechanisms of therapeutic antibodies.

What will go beyond "enhancing ADCC alone"? A major obstacle to predicting the critical mechanism that actually functions in patients is the lack of an appropriate animal model. The immune systems of animals are far different from that in humans in terms of effector functions; for example, the most widely used murine tumor models do not have the capacity to induce ADCC or CDC. ${ }^{95}$ Although several efforts to evaluate ADCC- or CDC-enhancing antibodies in vivo have been made to circumvent this limitation, such as the introduction of human effector cells into mice or establishing human Fc $\gamma$ RIII transgenic mice, the actual potency of engineered antibodies in the clinic is still difficult to foresee by using these models with limited clinical predictability. Monkey models would be effective tools to evaluate the in vivo activity of ADCC and/or CDC-based antibodies, ${ }^{48,77,96}$ however, the use of this model is limited for antibodies targeting leukocyte antigens. Importantly, good anti-tumor activity seen in the early-stage clinical trials of ofatumumab may provide a clue to this unanswered question; enhancing complement activation may add to the therapeutic efficacy of approved antibodies. We believe that the promising combination of the two clinically proven effector functions, namely ADCC and CDC, will be confirmed in future clinical trials of AccretaMAb antibodies. ${ }^{42,50,88}$

It is obvious that the choice of target functions of an antibody to be enhanced should be determined carefully based on a biological and mechanistic understanding of the target tumors and antigens, since various cancer subtypes of different origins display diverse biological profiles and resultant mechanisms of clinical resistance. Yet the major issue of current antibody therapy remains insufficient efficacy. Therefore, the expanding technologies that enhance multiple anti-tumor mechanisms of therapeutic antibodies would be of great value for the development of third-generation antibody therapeutics as long as they are used in the right patients, with the right dosage and on the right schedule, and perhaps monitored with appropriate biomarkers.

\section{Disclosure}

The authors report no conflicts of interest in this work.

\section{References}

1. Forero A, Lobuglio AF. History of antibody therapy for non-Hodgkin's lymphoma. Semin Oncol. 2003;30:1-5.

2. Grillo-López AJ. Rituximab (Rituxan/MabThera): the first decade (1993-2003). Expert Rev Anticancer Ther. 2003;3:767-779.

3. Vogel CL, Franco SX. Clinical experience with trastuzumab (herceptin). Breast J. 2003;9:452-462.

4. de Bono JS, Rowinsky EK. The ErbB receptor family: a therapeutic target for cancer. Trends Mol Med. 2002;8:S19-26.

5. Cartron G, Dacheux L, Salles G, et al. Therapeutic activity of humanized anti-CD20 monoclonal antibody and polymorphism in IgG Fc receptor FcgammaRIIIa gene. Blood. 2002;99:754-758.

6. Anolik JH, Campbell D, Felgar RE, et al. The relationship of FcgammaRIIIa genotype to degree of B cell depletion by rituximab in the treatment of systemic lupus erythematosus. Arthritis Rheum. $2003 ; 48: 455-459$.

7. Kim DH, Jung HD, Kim JG, et al. FCGR3A gene polymorphisms may correlate with response to frontline R-CHOP therapy for diffuse large B-cell lymphoma. Blood. 2006;108:2720-2725.

8. Musolino A, Naldi N, Bortesi B, et al. Immunoglobulin G fragment $\mathrm{C}$ receptor polymorphisms and clinical efficacy of trastuzumab-based therapy in patients with HER-2/neu-positive metastatic breast cancer. J Clin Oncol. 2008;26:1789-1796.

9. Weng WK, Levy R. Two immunoglobulin G fragment C receptor polymorphisms independently predict response to rituximab in patients with follicular lymphoma. J Clin Oncol. 2003;21:3940-3947.

10. Dall'Ozzo S, Tartas S, Paintaud G, et al. Rituximab-dependent cytotoxicity by natural killer cells: influence of FCGR3A polymorphism on the concentration-effect relationship. Cancer Res. 2004;64:4664-4669.

11. Gennari R, Menard S, Fagnoni F, et al. Pilot study of the mechanism of action of preoperative trastuzumab in patients with primary operable breast tumors overexpressing HER2. Clin Cancer Res. 2004;10:5650-5655.

12. Louis E, El Ghoul Z, Vermeire S, et al. Association between polymorphism in IgG Fc receptor IIIa coding gene and biological response to infliximab in Crohn's disease. Aliment Pharmacol Ther. 2004;19:511-519.

13. Miescher S, Spycher MO, Amstutz H, et al. A single recombinant anti$\mathrm{RhD}$ IgG prevents RhD immunization: association of $\mathrm{RhD}$-positive red blood cell clearance rate with polymorphisms in the FcgammaRIIA and FcgammaIIIA genes. Blood. 2004;103:4028-4035.

14. Treon SP, Hansen M, Branagan AR, et al. Polymorphisms in FcgammaRIIIA (CD16) receptor expression are associated with clinical response to rituximab in Waldenström's macroglobulinemia. J Clin Oncol. 2005;23:474-481.

15. Idusogie EE, Presta LG, Gazzano-Santoro H, et al. Mapping of the C1q binding site on rituxan, a chimeric antibody with a human IgG1 Fc. J Immunol. 2000;164:4178-4184.

16. Crowe JS, Hall VS, Smith MA, Cooper HJ, Tite JP. Humanized monoclonal antibody CAMPATH-1H: myeloma cell expression of genomic constructs, nucleotide sequence of cDNA constructs and comparison of effector mechanisms of myeloma and Chinese hamster ovary cell-derived material. Clin Exp Immunol. 1992;87:105-110.

17. Lobo ED, Hansen RJ, Balthasar JP. Antibody pharmacokinetics and pharmacodynamics. J Pharm Sci. 2004;93:2645-2668.

18. Lencer WI, Blumberg RS. A passionate kiss, then run: exocytosis and recycling of IgG by FcRn. Trends Cell Biol. 2005;15:5-9. 
19. Wahl AF, Klussman K, Thompson JD, et al. The anti-CD30 monoclonal antibody SGN-30 promotes growth arrest and DNA fragmentation in vitro and affects antitumor activity in models of Hodgkin's disease. Cancer Res. 2002;62:3736-3742.

20. Tai YT, Catley LP, Mitsiades CS, et al. Mechanisms by which SGN-40, a humanized anti-CD40 antibody, induces cytotoxicity in human multiple myeloma cells: clinical implications. Cancer Res. 2004;64:2846-2852.

21. Satoh M, Iida S, Shitara K. Non-fucosylated therapeutic antibodies as next-generation therapeutic antibodies. Expert Opin Biol Ther. 2006;6:1161-1173.

22. Farid SS. Process economics of industrial monoclonal antibody manufacture. J Chromatogr B Analyt Technol Biomed Life Sci. 2007;848:8-18.

23. Clark MR. IgG effector mechanisms. Chem Immunol. 1997;65:88-110.

24. Jefferis R, Lund J, Pound JD. IgG-Fc-mediated effector functions: molecular definition of interaction sites for effector ligands and the role of glycosylation. Immunol Rev. 1998;163:59-76.

25. Jefferis R, Lund J. Interaction sites on human IgG-Fc for FcgammaR: current models. Immunol Lett. 2002;82:57-65.

26. Morgan A, Jones ND, Nesbitt AM, Chaplin L, Bodmer MW, Emtage JS. The N-terminal end of the $\mathrm{CH} 2$ domain of chimeric human $\mathrm{IgG} 1$ anti-HLA-DR is necessary for C1q, Fc gamma RI and Fc gamma RIII binding. Immunology. 1995;86:319-324.

27. Walker MR, Lund J, Thompson KM, Jefferis R. Aglycosylation of human $\operatorname{IgG} 1$ and $\operatorname{IgG} 3$ monoclonal antibodies can eliminate recognition by human cells expressing Fc gamma RI and/or Fc gamma RII receptors. Biochem J. 1989;259:347-353.

28. Tao MH, Morrison SL. Studies of aglycosylated chimeric mouse-human $\mathrm{IgG}$. Role of carbohydrate in the structure and effector functions mediated by the human IgG constant region. J Immunol. 1989;143:2595-2601.

29. Krapp S, Mimura Y, Jefferis R, Huber R, Sondermann P. Structural analysis of human IgG-Fc glycoforms reveals a correlation between glycosylation and structural integrity. J Mol Biol. 2003;325:979-989.

30. Rademacher TW, Parekh RB, Dwek RA. Glycobiology. Annu Rev Biochem. 1988;57:785-838.

31. Mizuochi T, Taniguchi T, Shimizu A, Kobata A. Structural and numerical variations of the carbohydrate moiety of immunoglobulin G. J Immunol. 1982;129:2016-2020.

32. Harada H, Kamei M, Tokumoto Y, et al. Systematic fractionation of oligosaccharides of human immunoglobulin $\mathrm{G}$ by serial affinity chromatography on immobilized lectin columns. Anal Biochem. 1987;164:374-381.

33. Jefferis R. Glycosylation of human IgG antibodies: relevance to therapeutic applications. BioPharm. 2002;14:19-26.

34. Huber R, Deisenhofer J, Colman PM, Matsushima M, Palm W. Crystallographic structure studies of an IgG molecule and an Fc fragment. Nature. 1976;264:415-420.

35. Radaev S, Motyka S, Fridman WH, Sautes-Fridman C, Sun PD. The structure of a human type III Fcgamma receptor in complex with Fc. J Biol Chem. 2001;276:16469-16477.

36. Harris LJ, Skaletsky E, McPherson A. Crystallographic structure of an intact IgG1 monoclonal antibody. J Mol Biol. 1998;275:861-872.

37. Shields RL, Lai J, Keck R, et al. Lack of fucose on human IgG1 N-linked oligosaccharide improves binding to human Fcgamma RIII and antibodydependent cellular toxicity. J Biol Chem. 2002;277:26733-26740.

38. Baselga J, Albanell J. Mechanism of action of anti-HER2 monoclonal antibodies. Ann Oncol. 2001;12:S35-S41.

39. Berinstein NL, Grillo-López AJ, White CA, et al. Association of serum Rituximab (IDEC-C2B8) concentration and anti-tumor response in the treatment of recurrent low-grade or follicular non-Hodgkin's lymphoma. Ann Oncol. 1998;9:995-1001.

40. Goldenberg MM. Trastuzumab, a recombinant DNA-derived humanized monoclonal antibody, a novel agent for the treatment of metastatic breast cancer. Clin Ther. 1999;21:309-318.

41. Niwa R, Hatanaka S, Shoji-Hosaka E, et al. Enhancement of the antibody-dependent cellular cytotoxicity of low-fucose IgG1 Is independent of FcgammaRIIIa functional polymorphism. Clin Cancer Res. 2004;10:6248-55.
42. Niwa R, Shoji-Hosaka E, Sakurada M, et al. Defucosylated chimeric anti-CC chemokine receptor $4 \mathrm{IgG1}$ with enhanced antibody-dependent cellular cytotoxicity shows potent therapeutic activity to T-cell leukemia and lymphoma. Cancer Res. 2004;64:2127-2133.

43. Sliwkowski MX, Lofgren JA, Lewis GD, Hotaling TE, Fendly BM, Fox JA. Nonclinical studies addressing the mechanism of action of trastuzumab (Herceptin). Semin Oncol. 1999;4:60-70.

44. Lewis GD, Figari I, Fendly B, et al. Differential responses of human tumor cell lines to anti-p185HER2 monoclonal antibodies. Cancer Immunol Immunother. 1993;37:255-263.

45. Iida $\mathrm{S}$, Misaka $\mathrm{H}$, Inoue $\mathrm{M}$, et al. Nonfucosylated therapeutic $\operatorname{IgG} 1$ antibody can evade the inhibitory effect of serum immunoglobulin $\mathrm{G}$ on antibody-dependent cellular cytotoxicity through its high binding to FcgammaRIIIa. Clin Cancer Res. 2006;12:2879-2887.

46. Nechansky A, Schuster M, Jost W, et al. Compensation of endogenous IgG mediated inhibition of antibody-dependent cellular cytotoxicity by glyco-engineering of therapeutic antibodies. Mol Immunol. 2007;44:1815-1817.

47. Shields RL, Namenuk AK, Hong K, et al. High resolution mapping of the binding site on human IgG1 for FcgRI, FcgRII, FcgRIII, and FcRn and design of $\operatorname{IgG} 1$ variants with improved binding to the FcgR. J Biol Chem. 2001;276:6591-6604.

48. Lazar GA, Dang W, Karki S, et al. Engineered antibody Fe variants with enhanced effector function. Proc Natl Acad Sci U S A. 2006;103:4005-4010.

49. Stavenhagen JB, Gorlatov S, Tuaillon N, et al. Enhancing the potency of therapeutic monoclonal antibodies via Fc optimization. Adv Enzyme Regul. 2008;48:152-164.

50. Stavenhagen JB, Gorlatov S, Tuaillon N, et al. Fc optimization of therapeutic antibodies enhances their ability to kill tumor cells in vitro and controls tumor expansion in vivo via low-affinity activating Fcgamma receptors. Cancer Res. 2007;67:8882-8890.

51. Kanda Y, Yamada T, Mori K, et al. Comparison of biological activity among nonfucosylated therapeutic IgG1 antibodies with three different N-linked Fc oligosaccharides: the high-mannose, hybrid, and complex types. Glycobiology. 2007;17:104-118.

52. Yamane-Ohnuki N, Kinoshita S, Inoue-Urakubo M, et al. Establishment of FUT8 knockout Chinese hamster ovary cells: an ideal host cell line for producing completely defucosylated antibodies with enhanced antibody-dependent cellular cytotoxicity. Biotechnol Bioeng. 2004;87:614-622.

53. Niwa R, Sakurada M, Kobayashi Y, et al. Enhanced natural killer cell binding and activation by low-fucose IgG1 antibody results in potent antibody-dependent cellular cytotoxicity induction at lower antigen density. Clin Cancer Res. 2005;11:2327-2336.

54. Suzuki E, Niwa R, Saji S, et al. A nonfucosylated anti-HER2 antibody augments antibody-dependent cellular cytotoxicity in breast cancer patients. Clin Cancer Res. 2007;13:1875-1882.

55. Shinkawa T, Nakamura K, Yamane N, et al. The absence of fucose but not the presence of galactose or bisecting $\mathrm{N}$-acetylglucosamine of human IgG1 complex-type oligosaccharides shows the critical role of enhancing antibody-dependent cellular cytotoxicity. $J$ Biol Chem. 2003;278:3466-3473.

56. Niwa R, Natsume A, Uehara A, et al. IgG subclass-independent improvement of antibody-dependent cellular cytotoxicity by fucose removal from Asn297-linked oligosaccharides. J Immunol Methods. 2005;306:151-160.

57. Natsume A, Wakitani M, Yamane-Ohnuki N, et al. Fucose removal from complex-type oligosaccharide enhances the antibody-dependent cellular cytotoxicity of single-gene-encoded antibody comprising a single-chain antibody linked the antibody constant region. J Immunol Methods. 2005;306:93-103.

58. Natsume A, Wakitani M, Yamane-Ohnuki N, et al. Fucose removal from complex-type oligosaccharide enhances the antibody-dependent cellular cytotoxicity of single-gene-encoded bispecific antibody comprising of two single-chain antibodies linked to the antibody constant region. J Biochem (Tokyo). 2006;140:359-368. 
59. Shoji-Hosaka E, Kobayashi Y, Wakitani M, et al. Enhanced $\mathrm{Fc}$-dependent cellular cytotoxicity of $\mathrm{Fc}$ fusion proteins derived from TNF receptor II and LFA-3 by fucose removal from Asn-linked oligosaccharides. J Biochem. 2006;140:777-783.

60. Masuda K, Kubota T, Kaneko E, et al. Enhanced binding affinity for FcgammaRIIIa of fucose-negative antibody is sufficient to induce maximal antibody-dependent cellular cytotoxicity. Mol Immunol. 2007;44:3122-3131.

61. Mori K, Iida S, Yamane-Ohnuki N, Kanda Y, et al. Non-fucosylated therapeutic antibodies: the next generation of therapeutic antibodies. Cytotechnology. 2007;55:109-114.

62. Okazaki A, Shoji-Hosaka E, Nakamura K, et al. Fucose depletion from human IgG1 oligosaccharide enhances binding enthalpy and association rate between IgG1 and FcgammaRIIIa. J Mol Biol. 2004;336:1239-1249.

63. Matsumiya S, Yamaguchi Y, Saito J, et al. Structural comparison of fucosylated and nonfucosylated $\mathrm{Fc}$ fragments of human immunoglobulin G1. J Mol Biol. 2007;368:767-779.

64. Mori K, Kuni-Kamochi R, Yamane-Ohnuki N, et al. Engineering Chinese hamster ovary cells to maximize effector function of produced antibodies using FUT8 siRNA. Biotechnol Bioeng. 2004;88:901-908

65. Kanda Y, Yamane-Ohnuki N, Sakai N, et al. Comparison of cell lines for stable production of fucose-negative antibodies with enhanced ADCC. Biotechnol Bioeng. 2006;94:680-688.

66. Yamane-Ohnuki N, Yamano K, Satoh M. Biallelic gene knockouts in Chinese hamster ovary cells. Methods Mol Biol. 2008;435:1-16.

67. Kanda Y, Imai-Nishiya H, Kuni-Kamochi R, et al. Establishment of a GDP-mannose 4,6-dehydratase (GMD) knockout host cell line: a new strategy for generating completely non-fucosylated recombinant therapeutics. J Biotechnol. 2007;130:300-310.

68. Imai-Nishiya H, Mori K, Inoue M, et al. Double knockdown of alpha1,6-fucosyltransferase (FUT8) and GDP-mannose 4,6-dehydratase (GMD) in antibody-producing cells: a new strategy for generating fully non-fucosylated therapeutic antibodies with enhanced ADCC. BMC Biotechnol. 2007;7:84.

69. Ragupathi G, Liu NX, Musselli C, Powell S, Lloyd K, Livingston PO. Antibodies against tumor cell glycolipids and proteins, but not mucins, mediate complement-dependent cytotoxicity. J Immunol. 2005;174:5706-5712.

70. Cragg MS, Morgan SM, Chan HT, et al. Complement-mediated lysis by anti-CD20 mAb correlates with segregation into lipid rafts. Blood. 2003;101:1045-1052.

71. Bannerji R, Kitada S, Flinn IW, et al. Apoptotic-regulatory and complement-protecting protein expression in chronic lymphocytic leukemia: relationship to in vivo rituximab resistance. $J$ Clin Oncol. 2003;21:1466-1471.

72. Golay J, Lazzari M, Facchinetti V, et al. CD20 levels determine the in vitro susceptibility to rituximab and complement of B-cell chronic lymphocytic leukemia: further regulation by CD55 and CD59. Blood. 2001;98:3383-9.

73. Kennedy AD, Beum PV, Solga MD, et al. Rituximab infusion promotes rapid complement depletion and acute CD20 loss in chronic lymphocytic leukemia. J Immunol. 2004;172:3280-3288.

74. Treon SP, Mitsiades C, Mitsiades N, et al. Tumor cell expression of CD59 is associated with resistance to CD20 serotherapy in patients With B-cell malignancies. J Immunother. 2001;24:263-271.

75. Idusogie EE, Wong PY, Presta LG, et al. Engineered antibodies with increased activity to recruit complement. J Immunol. 2001;166:2571-2575.

76. Dall'Acqua WF, Cook KE, Damschroder MM, Woods RM, $\mathrm{Wu} \mathrm{H}$. Modulation of the effector functions of a human IgG1 through engineering of its hinge region. J Immunol. 2006;177:1129-1138.
77. Natsume A, In M, Takamura H, et al. Engineered antibodies of IgG1/ IgG3 mixed isotype with enhanced cytotoxic activities. Cancer Res. 2008;68:3863-3872.

78. Schumaker VN, Calcott MA, Spiegelberg HL, Muller-Eberhard HJ. Ultracentifuge studies of the binding of IgG of different subclasses to the Clq subunit of the first component of complement. Biochemistry. 1976;15:5175-5181.

79. Van Loghem E, Frangione B, Recht B, Franklin EC. Staphylococcal protein A and human IgG subclasses and allotypes. Scand J Immunol. $1982 ; 15: 275-278$.

80. Bruggemann M, Williams GT, Bindon CI, et al. Comparison of the effector functions of human immunoglobulins using a matched set of chimeric antibodies. J Exp Med. 1987;166:1351-1361.

81. Lutz R, Michael C, Herman W, Greg W. Reshaping human antibodies for therapy. Nature. 1988;332:323-327.

82. Zuckier LS, Chang CJ, Scharff MD, Morrison SL. Chimeric humanmouse IgG antibodies with shuffled constant region exons demonstrate that multiple domains contribute to in vivo half-life. Cancer Res. 1998;58:3905-3908.

83. Bowles JA, Wang SY, Link BK, et al. Anti-CD20 monoclonal antibody with enhanced affinity for CD16 activates NK cells at lower concentrations and more effectively than rituximab. Blood. 2006;108:2648-2654.

84. Hinton PR, Johlfs MG, Xiong JM, et al. Engineered human IgG antibodies with longer serum half-lives in primates. $J$ Biol Chem. 2004;279:6213-6216.

85. Dall'Acqua WF, Kiener PA, Wu H. Properties of human IgG1s engineered for enhanced binding to the neonatal $\mathrm{Fc}$ receptor $(\mathrm{FcRn})$. J Biol Chem. 2006;281:23514-23524.

86. Roopenian1 DC, Akilesh S. FcRn: the neonatal Fc receptor comes of age. Nat Rev Immunol. 2007;7:715-725.

87. Sondermann P, Huber R, Oosthuizen V, Jacob U. The 3.2-A crystal structure of the human IgG1 Fc fragment-Fc gammaRIII complex. Nature. 2000;406:267-273.

88. Coiffier B, Lepretre S, Pedersen LM, et al. Safety and efficacy of ofatumumab, a fully human monoclonal anti-CD20 antibody, in patients with relapsed or refractory B-cell chronic lymphocytic leukemia: a phase 1-2 study. Blood. 2008;111:1094-1100.

89. Vugmeyster Y, Beyer J, Howell K, et al. Depletion of B cells by a humanized anti-CD20 antibody PRO70769 in Macaca fascicularis. J Immunother. 2005;28:212-219.

90. Stein R, Qu Z, Chen S, et al. Characterization of a new humanized anti-CD20 monoclonal antibody, IMMU-106, and Its use in combination with the humanized anti-CD22 antibody, epratuzumab, for the therapy of non-Hodgkin's lymphoma. Clin Cancer Res. 2004;10:2868-2878.

91. Robak T. Novel monoclonal antibodies for the treatment of chronic lymphocytic leukemia. Curr Cancer Drug Targets. 2008;8:156-171.

92. Nimmerjahn F, Ravetch JV. Divergent immunoglobulin g subglass activity through selective Fc receptor binding. Science. 2005;310:1510-1512.

93. Gelderman KA, Tomlinson S, Ross GD, Gorter A. Complement function in mAb-mediated cancer immunotherapy. Trends Immunol. 2004;25:158-164

94. Jefferis R, Lund J, Mizutani H, et al. A comparative study of the $\mathrm{N}$-linked oligosaccharide structures of human IgG subclass proteins. Biochem J. 1990;268:529-537.

95. Bergman I, Basse PH, Barmada MA, Griffin JA, Cheung NK. Comparison of in vitro antibody-targeted cytotoxicity using mouse, rat and human effectors. Cancer Immunol Immunother. 2000;49:259-266.

96. Reff ME, Carner K, Chambers KS, et al. Depletion of B cells in vivo by a chimeric mouse human monoclonal antibody to CD20. Blood. 1994;83:435-445. 